Int. J. Morphol.,

35(1):273-286, 2017

\title{
Hallazgos Morfométricos y Funcionales Acerca de la Ínsula en Población VIH+ con Apatía
}

\author{
Morphometric and Functional Findings About the Insula in HIV+ Population with Apathy
}

Elba Beatriz Tornese ${ }^{1} \&$ Martín Javier Mazzoglio y Nabar ${ }^{2}$

TORNESE, E. B. \& MAZZOGLIO Y NABAR, M. J. Hallazgos morfométricos y funcionales acerca de la ínsula en población VIH+ con apatía. Int. J. Morphol., 35(1):273-286, 2017.

RESUMEN: La corteza insular es uno de los componentes de la zona paralímbica que presenta conexiones con áreas corticales y subcorticales. El estudio en personas viviendo con VIH (PVVIH), donde la apatía es frecuente, la implicó como modulador de respuesta emocional y ejecutiva. El objetivo es describir morfométricamente y funcionalmente la ínsula en relación con estructuras cerebrales corticales y subcorticales en PVVIH con apatía en comparación con controles y con PVVIH sin apatía, a fin de determinar su implicancia. Estudiamos 23 encéfalos de PVVIH de sexo masculino con apatía según evaluaciones neuropsiquiátricas. Se utilizó resonancia magnética $(\mathrm{RM})$ con protocolo cognitivo para cuantificación y tomografía por emisión de fotón único (SPECT) para evaluar la perfusión cortical, aplicados a: cortezas frontales, insulares, núcleos caudados y cuerpos amigdalinos. Registramos reducción significativa morfométrica de la corteza del cíngulo anterior izquierdo, núcleo caudado ipsilateral y cortezas dorso-laterales en VIH+ con apatía; la ínsula anterior registró una reducción no significativa $(\mathrm{p}=0,4)$. En el análisis funcional se determinó hipoperfusión en las cortezas del cíngulo anterior izquierdo, insular anterior izquierda y en el caudado de forma asimétrica; con hipoperfusiones relativas en regiones del hemisferio derecho. La perfusión de la ínsula anterior izquierda fue correlativa con la del caudado ipsilateral y proporcional a la severidad en el test de apatía. Concluimos que en la cohorte evaluada de pacientes viviendo con VIH y apatía hallamos un significativo compromiso funcional de la corteza insular anterior, correlativo con la afectación funcional y morfométrica de los núcleos caudados. La implicancia de la corteza insular sugiere su participación en la psicopatología de la apatía, parámetro vinculado con el déficit de interés por las actividades e iniciativas.

PALABRAS CLAVE: Ínsula; Apatía; VIH; RM; SPECT.

\section{INTRODUCCIÓN}

La corteza insular es uno de los componentes de la zona paralímbica con un rol crucial en la percepción y modulación de la sensibilidad, sensorialidad e información vegetativa que incluye al dolor y la sensibilidad visceral.

La ínsula yace profundamente en el trasfondo del surco lateral, entre la corteza sensitiva posterior y la corteza motora anterior, y consiste en un giro largo y 5 giros breves más anteriores. Sus regiones posterior y anterior (de giros breves) son divididas por la arteria cerebral media, la cual pasa a través de la superficie de esta corteza.

La corteza de la ínsula recibe aferencias de la corteza somatosensorial, de la auditiva y de los núcleos talámicos anteriores; proyecta eferencias a la corteza motora y al lóbulo temporal; pero sus conexiones bidireccionales son con muchas estructuras filogenéticamente nuevas como el opérculo parietal, los núcleos basales y las cortezas del cíngulo $\mathrm{y}$ frontales medial y orbitaria.

Se registró que la porción anterior de esta corteza está involucrada en el monitoreo de señales generadas en las vísceras (Critchley et al., 2004), en la detección e interpretación interoceptiva por lo cual se la denominó "centro de alarma interno". Muchas señales sensitivas desde el nervio vago culminan en esta corteza y se han aislado fuertes conexiones entre la ínsula anterior (correspondiente a los giros breves según la nomenclatura anatómica internacio-

\footnotetext{
${ }^{1}$ Médica. Doctora en Medicina, UBA. Médica Psiquiatra y Legista. Prof. Adj. (Eq) de Anatomía, Facultad de Medicina, UBA. Docente Autorizada del Departamento de Psiquiatría y Salud Mental, UBA. Jefe de Servicio, Hospital Moyano, GCABA.

${ }^{2}$ Médico. Especialista en Psiquiatría. Magister en Neurociencia y Biología del Comportamiento. Docente Adscripto de Anatomía, Facultad de Medicina, UBA.
} 
nal -NAI-) y la amígdala (cuerpo amigdalino según la nomenclatura anatómica internacional -NAI-), que se encargan de la respuesta emocional a señales somáticas (Augustine, 1996). Se describió que la corteza de la ínsula, a través de los cuerpos amigdalinos, juega un rol importante en la respuesta ansiógena (Etkin \& Wager, 2007); se objetivó mediante estudios neurofuncionales un aumento en la actividad (mayor en la izquierda) en respuesta a imágenes de caras en un grupo de estudiantes con diagnóstico de trastorno de ansiedad.

Otros estudios neurofuncionales hallaron hiperactivación de la corteza de la ínsula y los cuerpos amigdalinos en pacientes con diagnóstico de trastorno por estrés postraumático, pacientes con fobia social y con trastorno de ansiedad generalizada (Lorberbaum et al., 2004; Lindauer et al., 2008). Asimismo, se delimitaron las regiones anteriores y mediales de la corteza de la ínsula, hallándose activadas en sujetos controles en los momentos de anticipación a estímulos negativos (Schunck et al., 2008).

La porción anterior de la corteza insular es considerada como una parte del "cerebro social", puesto que tiene un rol principal en la respuesta de cooperación interpersonal durante el intercambio social. Otras de las funciones en que interviene esta región cortical cerebral son:

1) El control cardíaco (provee la codificación consciente de la actividad visceral y los sentimientos subjetivos ante dichos eventos).

2) El apetito (mediante señales desde el núcleo solitario que pasan por el núcleo ventro-póstero-medial del tálamo y junto con el opérculo frontal se reconocen como la "corteza principal del gusto").

3) En la excitación sexual en ambos sexos (Stoléru et al., 1999) y

4) En el dolor (a través de las señales aferentes dolorosas desde el nervio vago que finalizan en ambas ínsulas).

Cabe destacar que se reportó una disminución de la sustancia gris en la ínsula de pacientes con síndromes dolorosos y dichas disminuciones correlacionaron con la duración en años de la patología dolorosa (Schmidt-Wilcke et al., 2007).

En relación con la corteza insular posterior, las investigaciones la relacionan con el procesamiento de información de contenido somático, auditivo y del control de la musculatura somática. Distintos investigadores incluyen a la corteza de la ínsula posterior como parte del circuito involucrado en el procesamiento afectivo, particularmente relacionado con la ansiedad (Simmons et al., 2006).
El estudio de la corteza insular en pacientes con deterioro neurocognitivo no ha sido muy desarrollado. Distintos grupos de investigación estudiaron su implicancia anatómica en demencias degenerativas primarias como la Demencia tipo Alzheimer, pero su implicancia en la conectividad morfométrica y correlato anátomo-funcional se encuentran en investigación y revisión. Nuestro grupo de investigación, en un estudio sobre 38 pacientes con Demencia tipo Alzheimer (DTA), determinó su reducción morfométrica en ambos sexos con mayor focalización en la región anterior, la cual fue correlativa con el tiempo de evolución de la enfermedad degenerativa y con la reducción volumétrica de estructuras paleocorticales del lóbulo temporal en el caso de las pacientes mujeres y de estructuras orbitarias en los hombres estudiados (Tornese \& Mazzoglio y Nabar, 2012).

El virus de la inmunodeficiencia humana (VIH) ingresa al sistema nervioso central durante el periodo de la primoinfección, de forma muy temprana a través del sistema fagocítico-mononuclear traspasa la barrera hematoencefálica y puede generar síntomas neuropsiquiátricos. Estudios de investigación determinaron que uno de los lugares neuroanatómicos donde se asienta con mayor prevalencia y cantidad son los núcleos de la base. Al inicio de la infección no se objetivan alteraciones neurocognitivas, si bien el deterioro de las funciones cognitivas comienza con la primoinfección y es subclínico, presentando un patrón de deterioro de tipo subcortical, puesto el virus afecta estructuras subcorticales y la sustancia blanca con mayor impacto.

Mediante el uso de neuroimágenes estructurales (Resonancia Magnética-RM) y/o funcionales (Tomografía por emisión fotón único -SPECT- o por emisión de positrones PET-) se objetivan cambios neuroanatómicos en los cerebros de sujetos infectados que son correlativos con la aparición de signos y síntomas en la clínica neuropsiquiátrica de los pacientes. En nuestros estudios preliminares con neuroimágenes objetivamos alteraciones corticosubcorticales en pacientes con alteraciones neurocognitivas asociadas al VIH en pacientes con y sin trastorno depresivo, el cual presentaba un patrón de perfusión correlativo con los síntomas clínicos y con alteraciones bioquímicas (Mazzoglio y Nabar, 2007, 2014; Tornese \& Mazzoglio y Nabar, 2008, 2009, 2011, 2012).

Una de las patologías con alta frecuencia durante la infección por VIH es la apatía (Paul et al., 2005), definida clínicamente como una ausencia o pérdida de sentimientos, emociones, interés o inquietud. La apatía también se reportó en otras enfermedades (Enfermedad de Parkinson, DTA). Se sugirió que las alteraciones mnésicas de trabajo en VIH+ son más prevalentes en presencia de apatía. 
El objetivo del presente trabajo es describir morfométricamente y funcionalmente la ínsula en relación con estructuras cerebrales corticales y subcorticales en personas viviendo con VIH (PVVIH) con apatía comparadas con controles y con PVVIH sin apatía, a fin de determinar su implicancia.

\section{MATERIAL Y MÉTODO}

El grupo de estudio estuvo conformado por 23 encéfalos pertenecientes a personas viviendo con VIH de sexo masculino, edades entre 28 a 49 años (promedio=37.23,
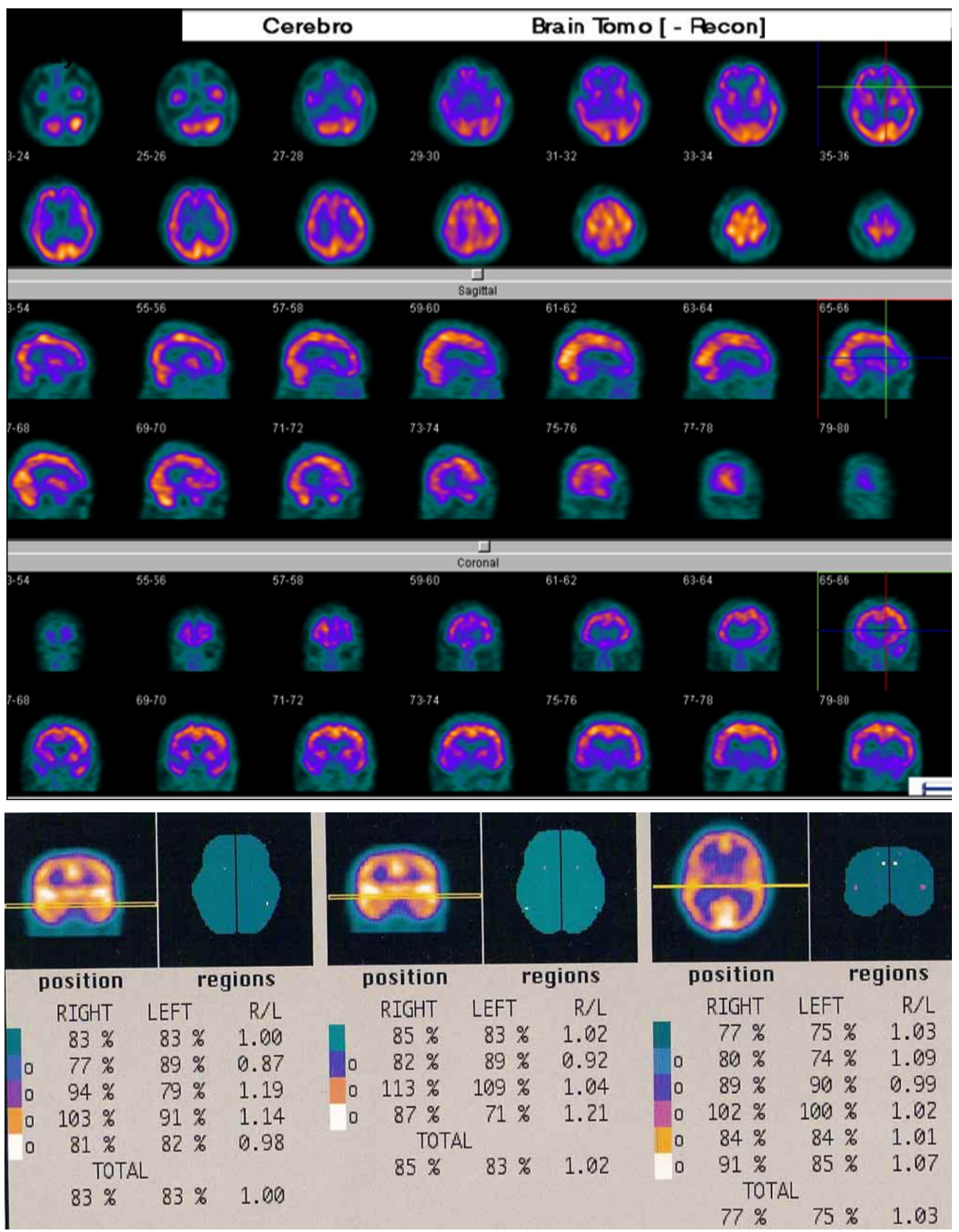

Fig. 1. Imágenes de SPECT de sujeto VIH+ con apatía con análisis semicuantitativo. 
$\mathrm{DS}=8.6$ ), todos medicados con terapia antirretroviral de gran actividad (TARGA) y con signo-sintomatología apática.

El grupo de comparación estuvo conformado por 25 encéfalos pertenecientes a hombres viviendo con VIH, cuyas edades fluctuaban entre 25 y 50 años (promedio $=34,6$; $\mathrm{DS}=7,2$ ), todos medicados con terapia antirretroviral de gran actividad (TARGA) y sin signo-sintomatología apática. El grupo control estuvo conformado por 30 hombres, cuyas edades fluctuaban entre 25 y 50 años (promedio $=35,1$; $\mathrm{DS}=6,4)$ con serología negativa para VIH y sin apatía.

Los criterios de inclusión al presente trabajo de investigación fue que los pacientes pertenecieran al sexo masculino, con serología positiva para VIH por método de ELISA, cargas virales negativizadas ( $<50$ copias ARN $/ \mathrm{ml}$ ) mayor a 5 años de evolución sostenida, en tratamiento con antirretrovirales de gran actividad y con evolución de la enfermedad mayor a 5 años. Dichos criterios se fundamentan en: los hombres no presentan disrupciones hormonales que puedan alterar la esfera tímica al momento de evaluación psicopatológica, la carga viral negativizada y el uso de TARGA mayor a 5 años disminuye la predisposición a otras enfermedades asociadas en el sistema nervioso, que pudiesen generar sesgos y provee de un tiempo de restitución inmunológica.
Fueron criterios de exclusión: deterioro neurocognitivo, uso de medicación psicofarmacológica, patologías neurológicas centrales, otros trastornos mentales o del comportamiento, uso de sustancias adictivas, enfermedades autoinmunes o sistémicas, enfermedades hematológicas o vasculares centrales, antecedente de traumatismo craneoencefálico o neurocirugías.

Ambos grupos recibieron evaluación neuropsicológica y neuropsiquiátrica con el examen del Estado Mental Mínimo de Folstein et al. (Folstein et al.,1975), la Escala de Deterioro Global de Reisberg y cols. (Reisberg et al., 1982), el Test de Dominancia Manual adaptado de Tornese y Mascitti (Tornese \& Mascitti, 1994), 1a MINI Entrevista Neuropsiquátrica Internacional (Sheehan et al 1998), y se aplicaron 2 escalas para la valoración de trastorno depresivo (PHQ-9 y Hamilton Depression Rating Scale-HDRS-) (Kroenke et al., 2002; Hamilton, 1976) y una escala de apatía (Escala de evaluación de Apatía versión clínica "AES-C"; Marin, 1996) (Marin, 1996).

Posteriormente, se estudiaron los encéfalos de ambos grupos con neuroimágenes estructurales (RM con protocolo cognitivo para cuantificación volumétrica) y funcionales (SPECT 99Tc-ECD para evaluar la perfusión).

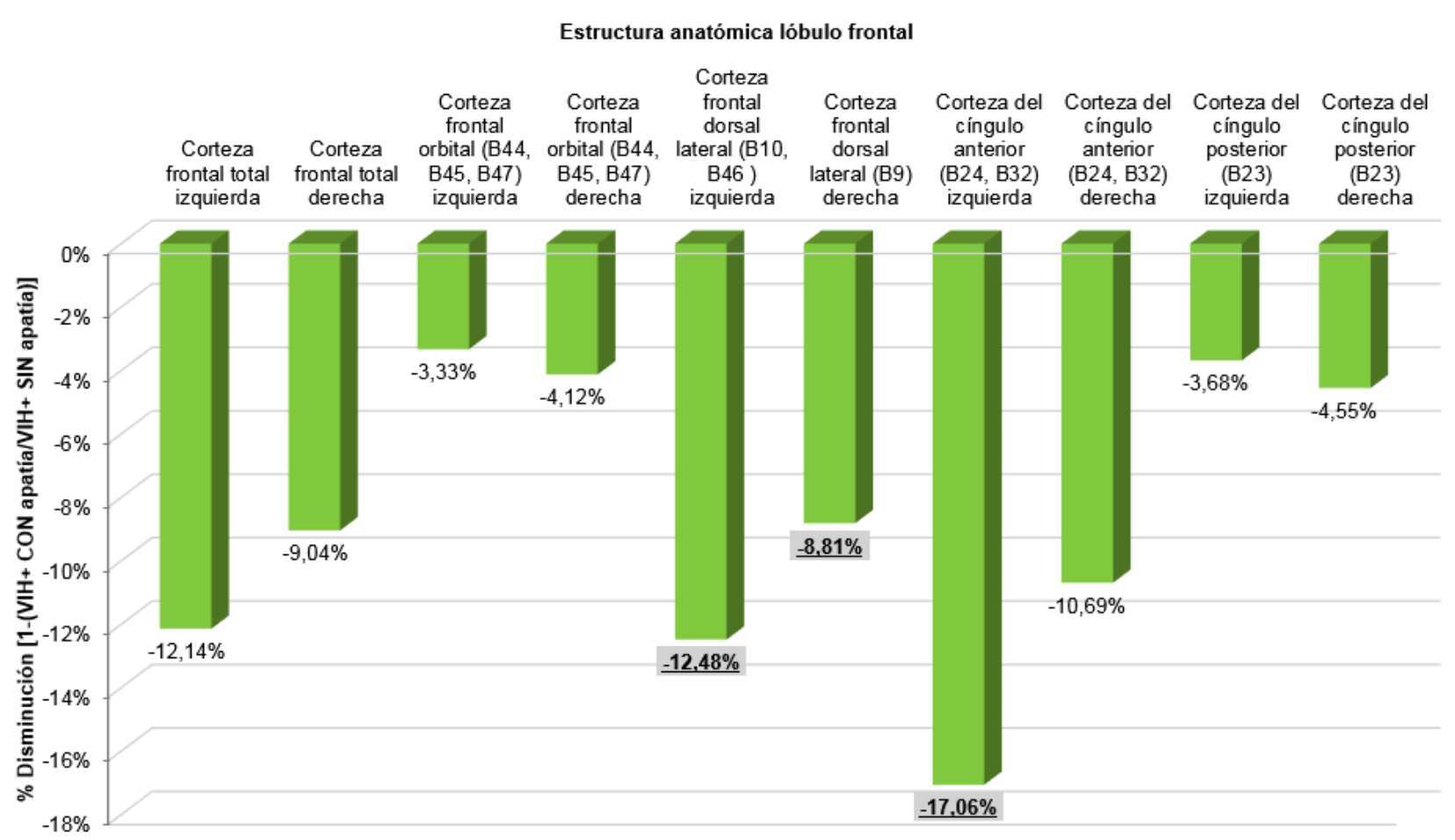

Fig. 2. Porcentaje de disminución volumétrica entre sujetos VIH+ con apatía y sin apatía en las cortezas frontales cuantificadas por RM (En negrita, subrayado y con fondo gris aquellos datos con significación estadística) 
El estudio morfométrico se realizó con un Resonador magnético de $1.5 \mathrm{~T}$ y se exploraron regiones solicitadas en secuencias que ponderan los tiempos de relajación tisulares T1, T2 y FLAIR, con registro en planos axial, coronal y sagital. Las imágenes en T1 fueron realizadas mediante cortes de $1,5 \mathrm{~mm}$ en el plano axial y secuencias de $1,5 \mathrm{~mm}$ y $3 \mathrm{~mm}$ en el plano coronal perpendiculares al eje del plano temporal y del eje mayor encefálico, las que luego fueron obtenidas por gradiente de 3D con extracción de artificios y reconstrucción de imágenes estáticas firmes. La cuantificación de imágenes fue llevada a cabo en 3 pasos por un análisis de procesamiento de datos semiautomático en que las mismas fueron procesadas con la opción region of interest (ROI) que se corrigieron manualmente y se determinó la morfometría en ambos hemisferios de: corteza prefrontal (CPF), corteza insular (CI), núcleos caudados (NC) y cuerpos amigdalinos (CA).

La cuantificación volumétrica de la corteza prefrontal se obtuvo tomando como parámetros los límites descriptos por Wible et al (Wible, 1995).

La cuantificación volumétrica de la corteza insular se obtuvo mediante los parámetros publicados en el protocolo de Crespo-Facorro et al (2000). Este protocolo considera los márgenes dorsales y ventrales de la corteza insular definidos por los surcos circulares insulares superior e inferior. La fusión entre los surcos circulares de la ínsula con el fondo del surco lateral es el límite posterior de la ínsula. El surco órbitoinsular se lo toma como límite inferior.

La cuantificación del cuerpo amigdalino (Fig. 1) se realizó acorde con protocolos normatizados en secuencias realizadas en cortes coronales finos perpendiculares al eje del plano temporal (protocolo "cognitivo"). Si bien se realiza junto con la identificación del hipocampo, para la mejor delimitación del límite entre el hipocampo y el cuerpo amigdalino se recurre a la herramienta Orthogonal sections utilizada en morfometría, según trabajos de normatización de Bhatia et al y delimitaciones morfométricas de Pruessner et al. (2000). Para su delimitación anatómica se pueden usar cortes axiales y coronales. Los cortes axiales sirven para delimitar los márgenes laterales y mediales del cuerpo amigdalino. En los cortes inferiores, el cuerpo amigdalino quedaría delimitado por la sustancia gris adyacente, anterior y lateralmente a la corteza entorrinal, y posteriormente por el asta temporal del ventrículo lateral y por el hipocampo. En los cortes más superiores, el límite anterior se delimita por el gyrus ambiens y posteriormente por el ventrículo lateral. Los cortes coronales se usan para delimitar más precisamente el límite posterior del cuerpo amigdalino, en el punto donde la sustancia gris aparece por encima del alveus y lateralmente al hipocampo.
El estudio neurofuncional se realizó con Tomografía por Emisión de Fotón Único (TEFU o SPECT según siglas en inglés) con aplicación del radiotrazador 99Tc-ECD para evaluar la perfusión cortical cerebral (Fig. 2). Los datos fueron reconstruidos mediante método OSEM, realizando corrección de atenuación (método de Chang) (Chang, 1979) y análisis semi-cuantitativo de la perfusión cortical o flujo sanguíneo cortical "FSC" (método de Tanaka et al., 2000) aplicado a las cortezas frontal e insular, núcleos caudados y cuerpo amigdalino (Fig. 3). Para la clasificación del FSC se utilizó el parámetro, acorde con los reportes internacionales, que aquellas perfusiones con diferencias mayores a 2DS de la perfusión normatizada para la zona anatómica presentan una alteración absoluta de la perfusión (hipo o hiperperfusión absoluta) y aquellas entre 1DS y 2DS presentaban una alteración de la perfusión relativa (hipo o hiperperfusión relativa). Luego se comparó la disminución de los valores perfusiones entre el grupo con apatía y sin apatía.

Obtenidos los datos, se realizó el análisis estadístico descriptivo e inferencial de los parámetros anatómicos para ambos grupos (promedio, desvío estándar(DS), máximo, mínimo, diferencia porcentual entre promedios de grupos, coeficiente de correlación $r$ y coeficiente de implicancia entre variables $\mathrm{r}^{2}$ ). Para realizar la significación estadística de los parámetros cuantificados volumétricamente se utilizó el Test de Student (t-Test) y la significación estadística se definió como p $<0.01$. El análisis estadístico fue realizado con el programa Microsoft Excel $^{\circledR} 2010$ para Windows XP.

Se tomaron como reparos éticos el requerimiento del consentimiento informado de los intervinientes previo a la realización de los test psicopatológicos y las neuroimágenes, manteniendo bajo reserva su identidad. La presente investigación cumple con los requisitos estipulados por las GCP (Good Clinical Practice), la Disposición ANMAT 6677/10 y adhiere a los Principios Éticos que tienen origen en la Declaración de Helsinski.

\section{RESULTADOS}

Todos los sujetos evaluados presentaban dominancia manual derecha.

Objetivamos una disminución morfométrica en las estructuras anatómicas cuantificadas (con diferencias en su significación estadística), excepto en la corteza insular posterior derecha que se halló un aumento del $1.03 \%$ no significativo. 
Las reducciones morfométricas significativas $(\mathrm{p}<0.01)$ a nivel cortical y de núcleos subcorticales en sujetos VIH+ con apatía en comparación con aquellos sin apatía, según severidad, fueron cuantificadas en: corteza del cíngulo anterior izquierda $(17,06 \%)$, corteza frontal dorsal lateral izquierda (12,48\%), núcleo caudado izquierdo (10,34 $\%$ ) y corteza frontal dorsal lateral derecha $(8,81 \%)$. La corteza frontal total izquierda y la del cíngulo anterior derecha presentaron reducciones volumétricas con menor significación estadística $(\mathrm{p}<0.1)$; el resto de las estructuras anatómicas estudiadas presentaron reducciones no significativas (Figs. 4 and 5).

En el estudio de la sustancia blanca hallamos que el sistema de fibras del lóbulo frontal y de la ínsula presentaba reducciones. Sólo presentaron disminuciones volumétricas

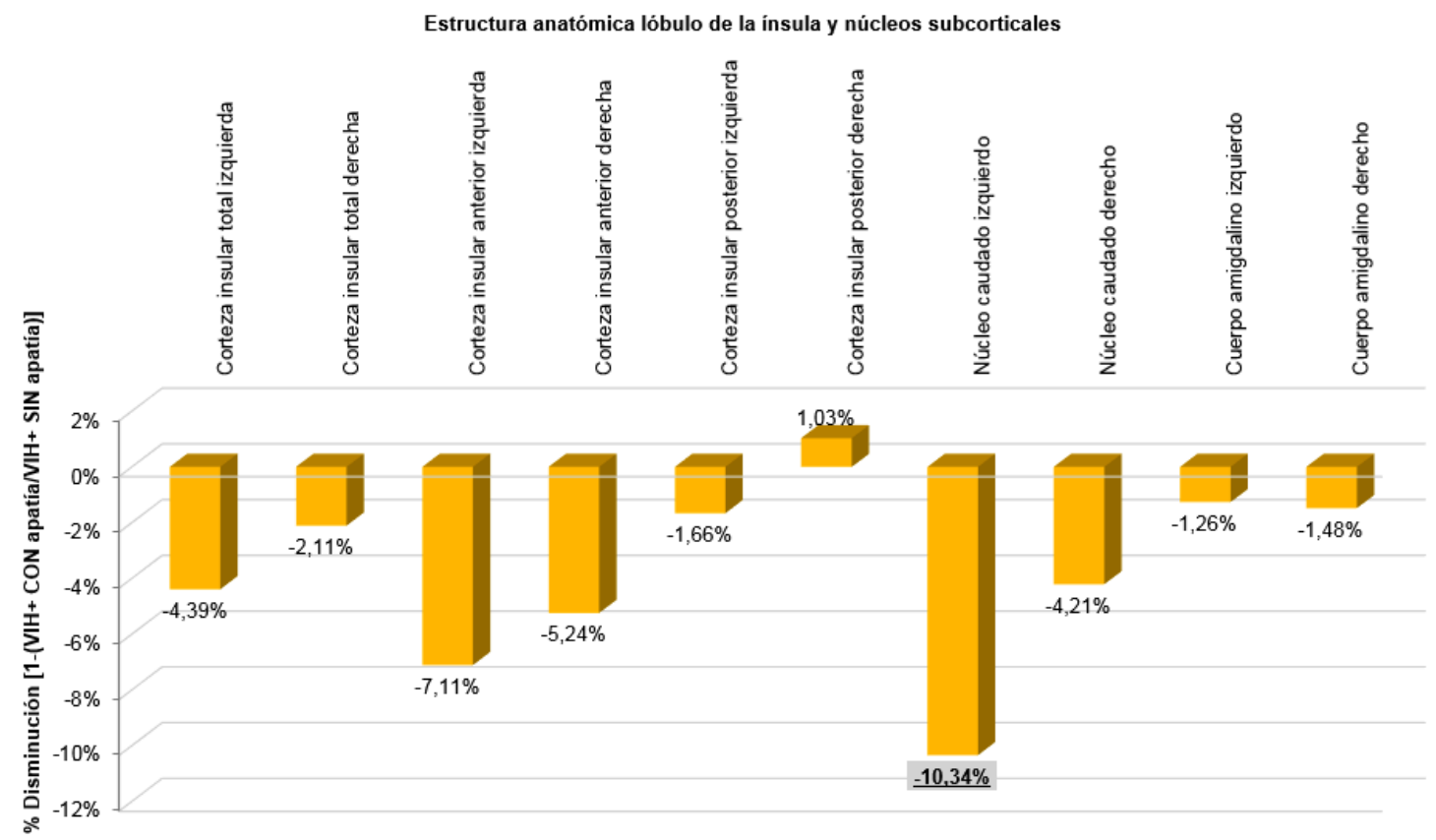

Fig. 3. Porcentaje de disminución volumétrica entre sujetos VIH+ con apatía y sin apatía en las cortezas de la ínsula y los núcleossubcorticales. (En negrita, subrayado y con fondo gris aquellos datos con significación estadística).

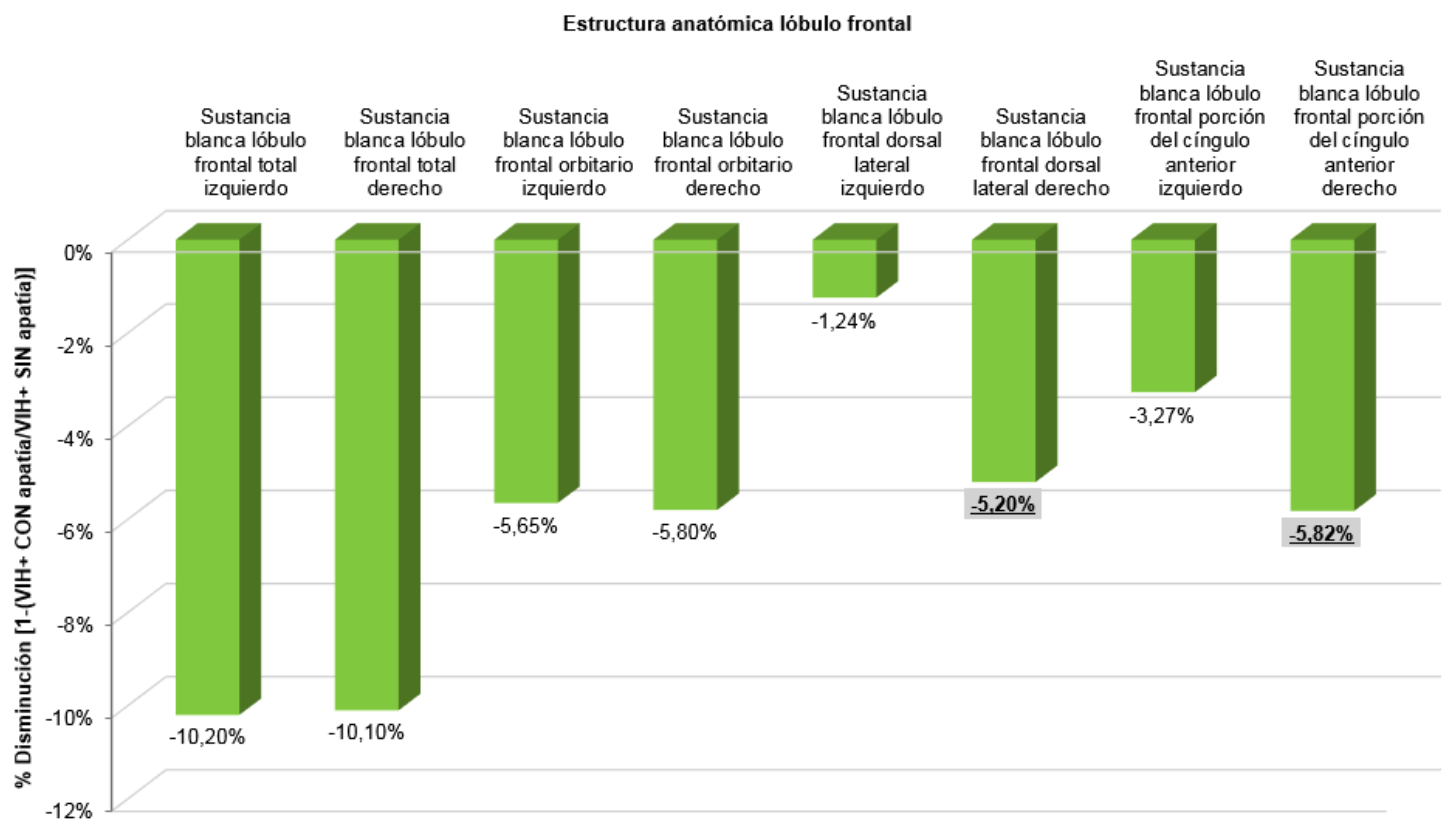

Fig. 4. Porcentaje de disminución volumétrica entre sujetos VIH+ con apatía y sin apatía en sustancia blanca del lóbulo frontal. (En negrita, subrayado y con fondo gris aquellos datos con significación estadística). 
significativas, según severidad, la sustancia blanca del lóbulo frontal porción del cíngulo anterior derecho $(-5,82 \%)$ y la sustancia blanca lóbulo del frontal dorsal lateral derecho $(-5,20 \%)$. Las otras estructuras que presentaron reducciones con una significación $\mathrm{p}<0.1$ (debajo del nivel de corte para este tipo de estudio) correspondieron a estructuras del lóbulo frontal.(Fig. 4).
$\mathrm{Al}$ analizar las disminuciones volumétricas entre los hemisferios cerebrales hallamos que las reducciones corticales significativas se presentaron en el izquierdo (sólo una en el derecho) y el promedio de disminuciones corticales de las estructuras analizadas casi duplican a las del derecho (izquierdas $=-7,20 \%$ vs derechas $=-4,45 \%$ ), presentándose las mayores reducciones en los lóbulos frontales (Fig. 5). Las reducciones

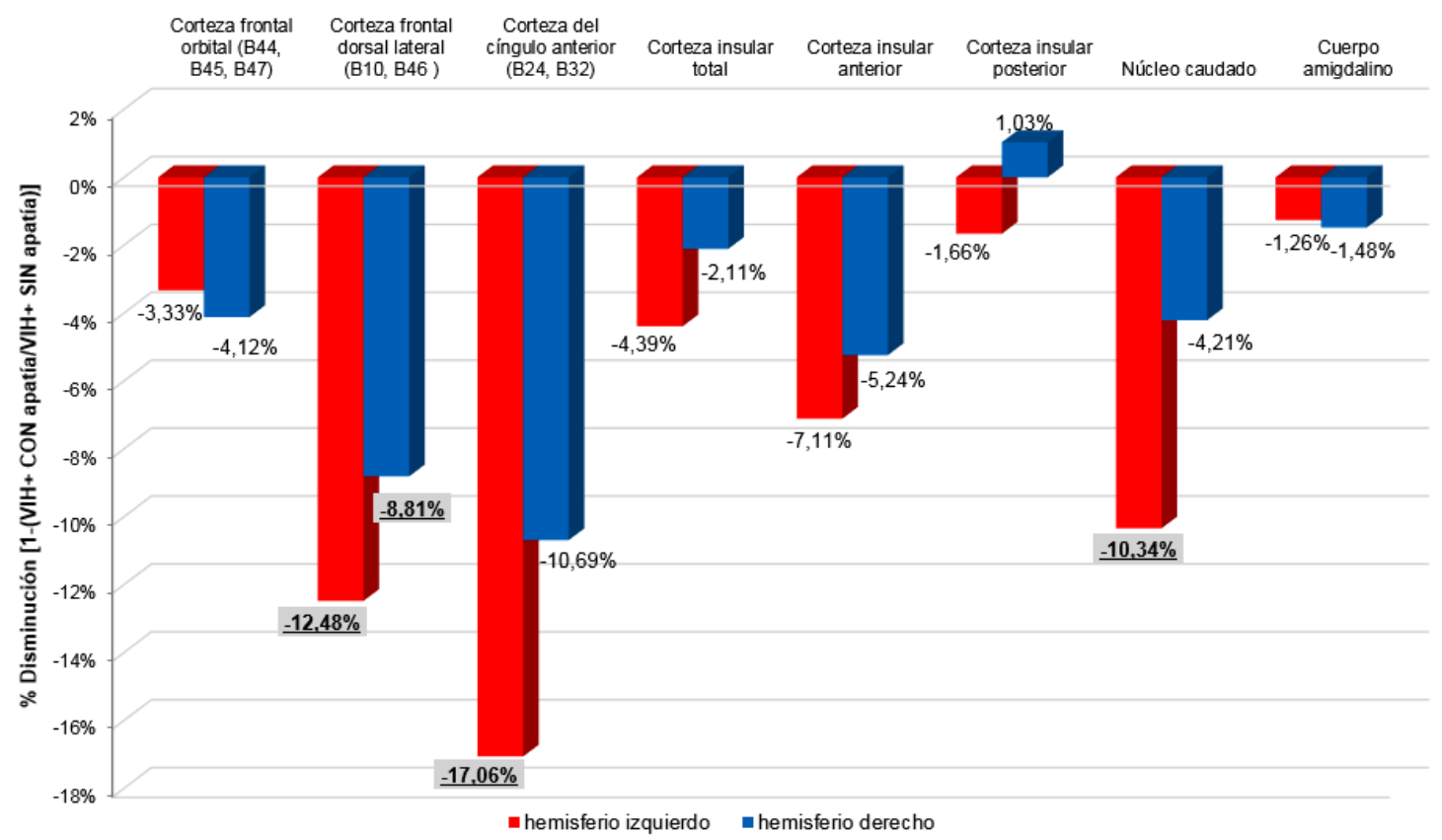

Fig. 5. Porcentaje de disminución volumétrica en cortezas frontales, de la ínsula, núcleo caudado y cuerpo amigdalino según hemisferio entre sujetos VIH+ con apatía y sin apatía cuantificadas por RM.

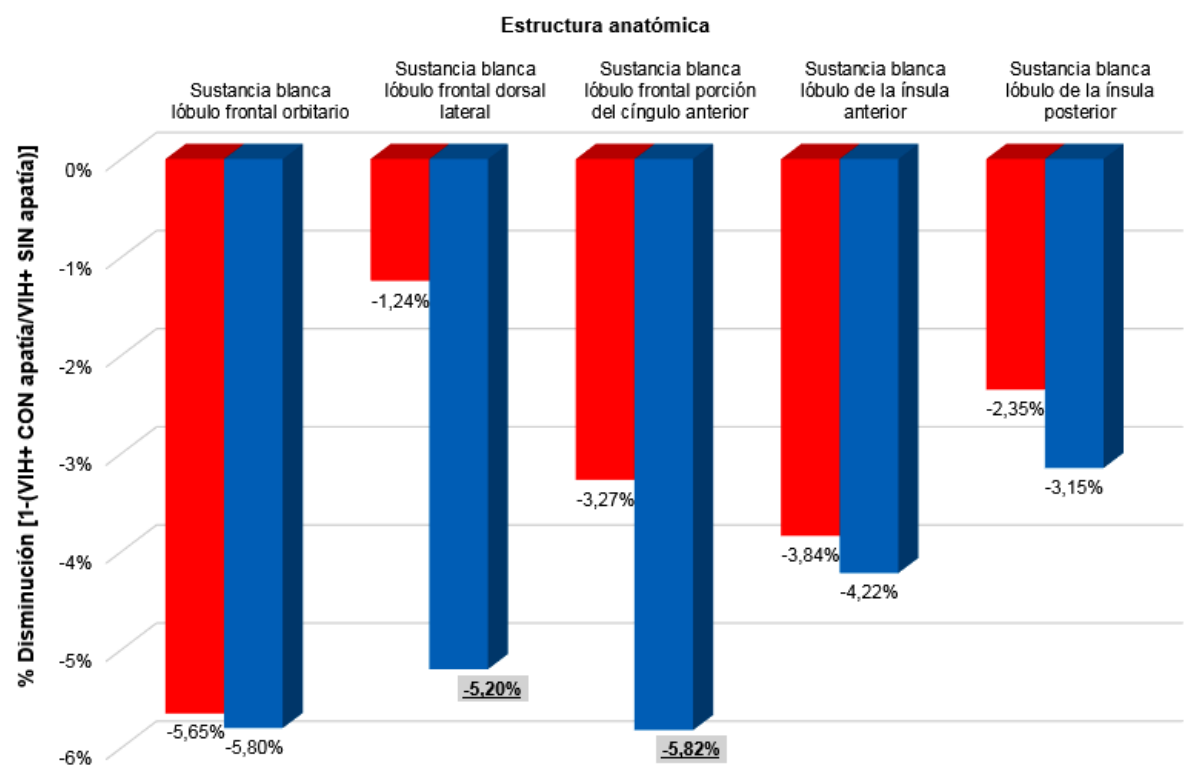

Fig. 6. Porcentaje de disminución volumétrica en la sustancia blanca de los lóbulos frontales y de la ínsula según hemisferio entre sujetos VIH+ con apatía y sin apatía cuantificadas por RM. 
de la sustancia blanca significativas se hallaron en el hemisferio derecho y correspondieron ambas a estructuras del lóbulo frontal; el promedio de las disminuciones de sustancia blanca de las estructuras analizadas fue un casi un $50 \%$ mayor a las del izquierdo (izquierdas=-3,27 \% vs derechas $=-4,84 \%$ ) (Fig. 6).
El análisis semicuantitativo aplicado a las neuroimágenes funciones por SPECT determinó hipoperfusiones absolutas, según severidad, en (Fig.7) :

· corteza del cíngulo anterior izquierda AC1 y AC2 (-20.25\%)

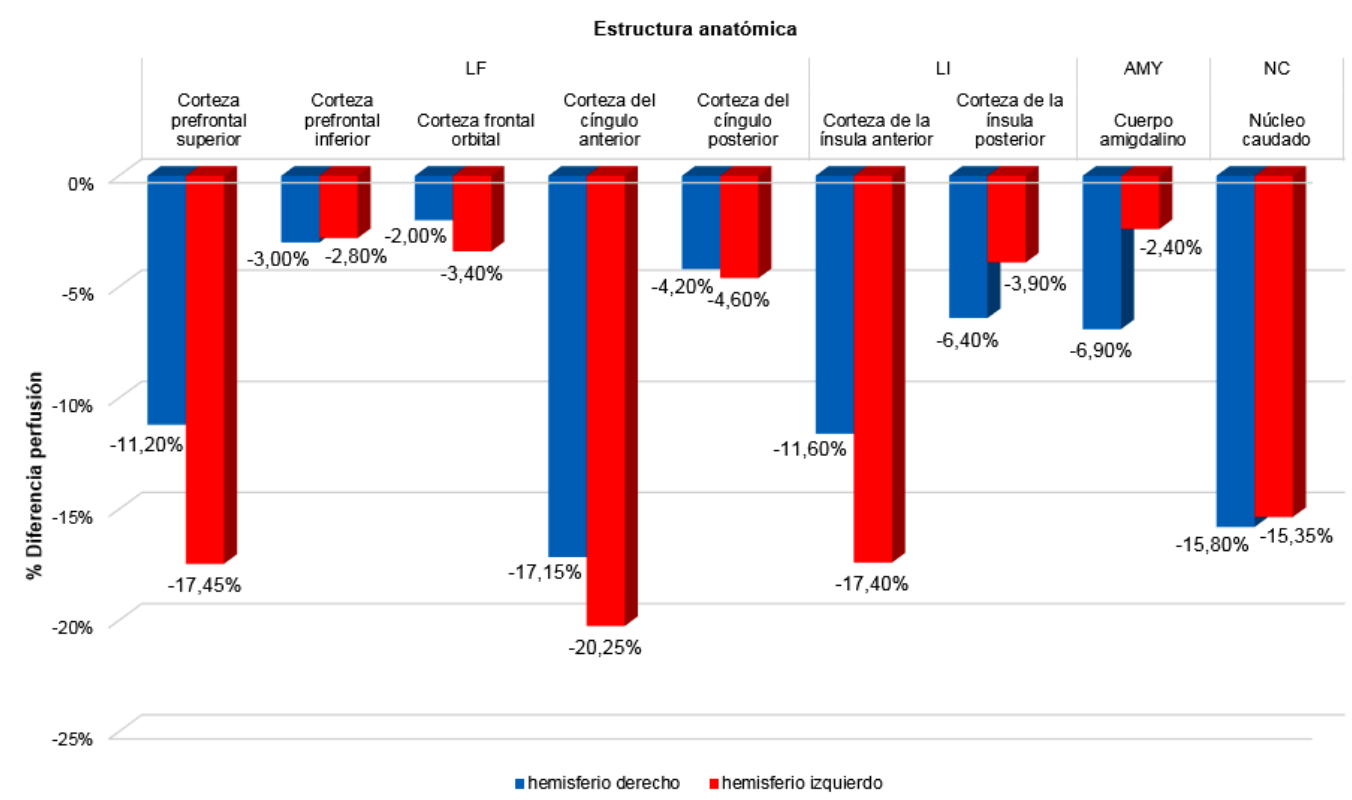

Fig. 7. Diferencias perfusionales según hemisferio registradas entre sujetos VIH+ con apatía y sin apatía, con especificación de la parcelación anatómica lobar y sin discriminación de áreas.

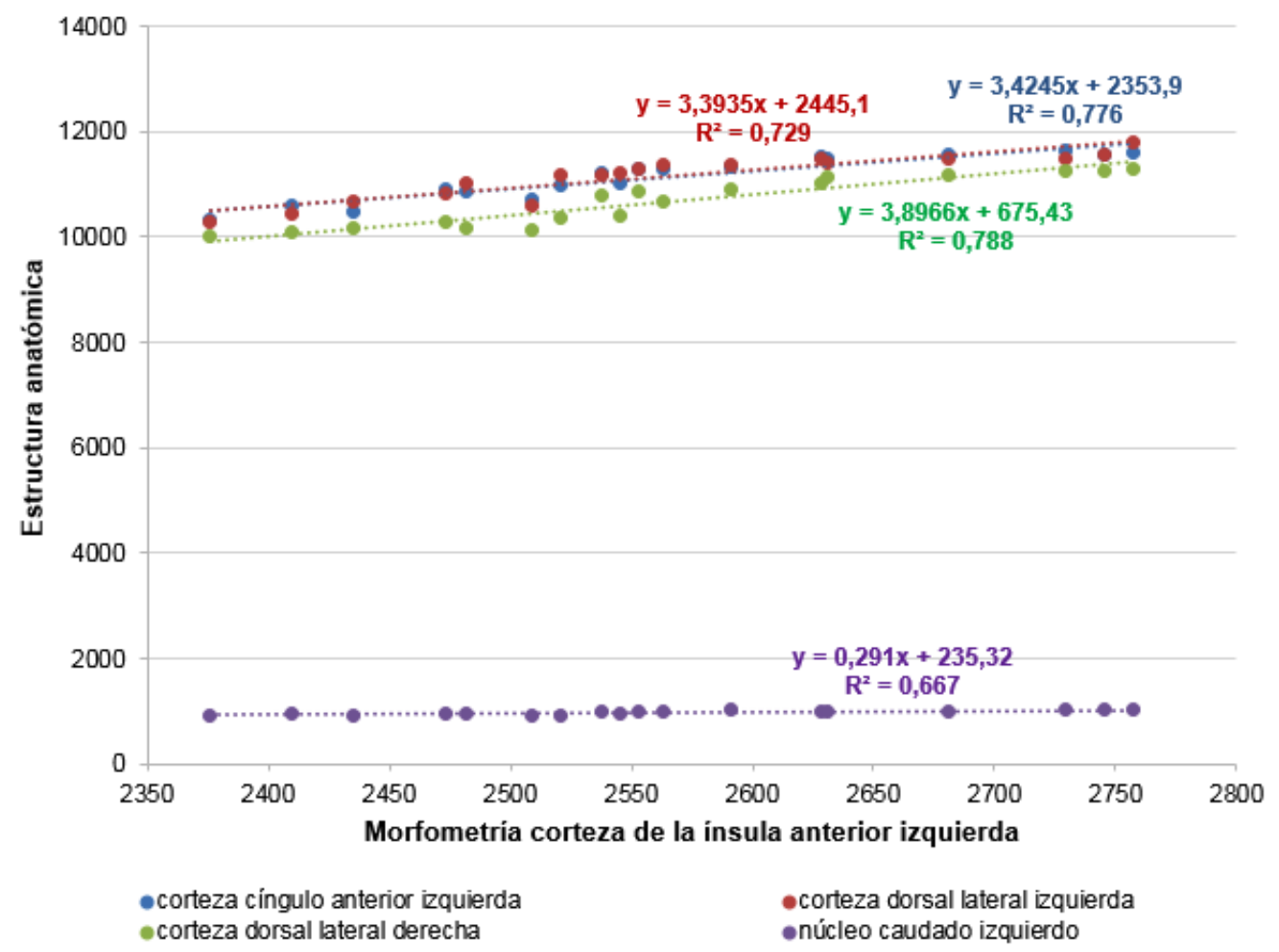

Fig. 8. Correlación entre la morfometría de la ínsula anterior izquierda y la cuantificación morfométrica de las cortezas del cíngulo anterior y dorsal lateral bilaterales en pacientes viviendo con VIH con apatía. 
- corteza prefrontal superior izquierda SPF1 y SPF2 (-17.45\%). - corteza de la ínsula anterior izquierda IA e IP (-17.40\%). - corteza del cíngulo anterior derecho AC1 y AC2 (-17.15\%). - núcleo caudado derecho NC1 y NC2 (-15.80 \%).

- núcleo caudado izquierdo NC1 y NC2 (-15.35\%) con predominio anterior.

- corteza prefrontal superior SPF1 y SPF2 derecha (-11.20 $\%)$.

Destacamos que la corteza de la ínsula anterior derecha (IA) y el núcleo caudado izquierdo en su porción posterior (NC2) presentaron hipoperfusiones relativas. Al analizar las hipoperfusiones por estructura, sin discriminación según grilla de Tanaka ni subdivisiones anatómicas, el núcleo caudado derecho presentó la mayor afectación $(-15,80 \%)$, seguido por su contralateral $(-15,35 \%)$ y el lóbulo de la ínsula izquierdo $(-10,65 \%)$.

Por gráfico de correlación aplicado a los resultados significativos de la neuroimagenología estructural, funcional y de los testneuropsicológicos y neuropsiquiátricos determinamos en PVVIH con apatía que:

- la morfometría de la corteza de la ínsula izquierda en su porción anterior presentó correlación e implicancia con la morfometría de la corteza dorsal y lateral derecha $\left(\mathrm{r}^{2}=\right.$ $0,79)$, y corteza del cíngulo anterior ipsilateral $\left(r^{2}=0,77\right)$ (Fig. 8), sin hallar correlación entre su morfometría con los valores del test de apatía ni con la volumetría de la sustancia blanca que presentó disminución significativa;

- la morfometría del núcleo caudado izquierdo presentó correlación e implicancia con la morfometría de las cortezas dorsal $\left(r^{2}=0.76\right)$ y lateral derecha e izquierda $\left(r^{2}=0,74\right)$ (Fig. 9); y una correlación entre su anatomía volumétrica con la subescala cognitiva de la AES-C (Fig. 10);

- la morfometría de la sustancia blanca dorsal y lateral derecha como la del cíngulo anterior ipsilateral no presentaron correlaciones significativas con los resultados del test aplicado para apatía, si bien se halló una tendencia leve con los resultados de la subescala cognitiva;

- la perfusión de la corteza de la ínsula IA izquierda presentó correlación con la perfusión del núcleo caudado izquierdo ( $\left.\mathrm{NC} 1: \mathrm{r}^{2}=0,84\right)$ y derecho $\left(\mathrm{NC} 2: \mathrm{r}^{2}=0,83\right)$, con la corteza del cíngulo anterior izquierda $\left(\mathrm{AC} 2: \mathrm{r}^{2}=0,77 ; \mathrm{AC} 1\right.$ : $\mathrm{r}^{2}=0,75$ ) (Fig. 11) y se objetivó correlación e implicancia con el puntaje total en la AES-C $\left(r^{2}=0,80\right)$ y de la subescala emocional $\left(r^{2}=0,71\right)$ (Figs. 12 y 13$)$.

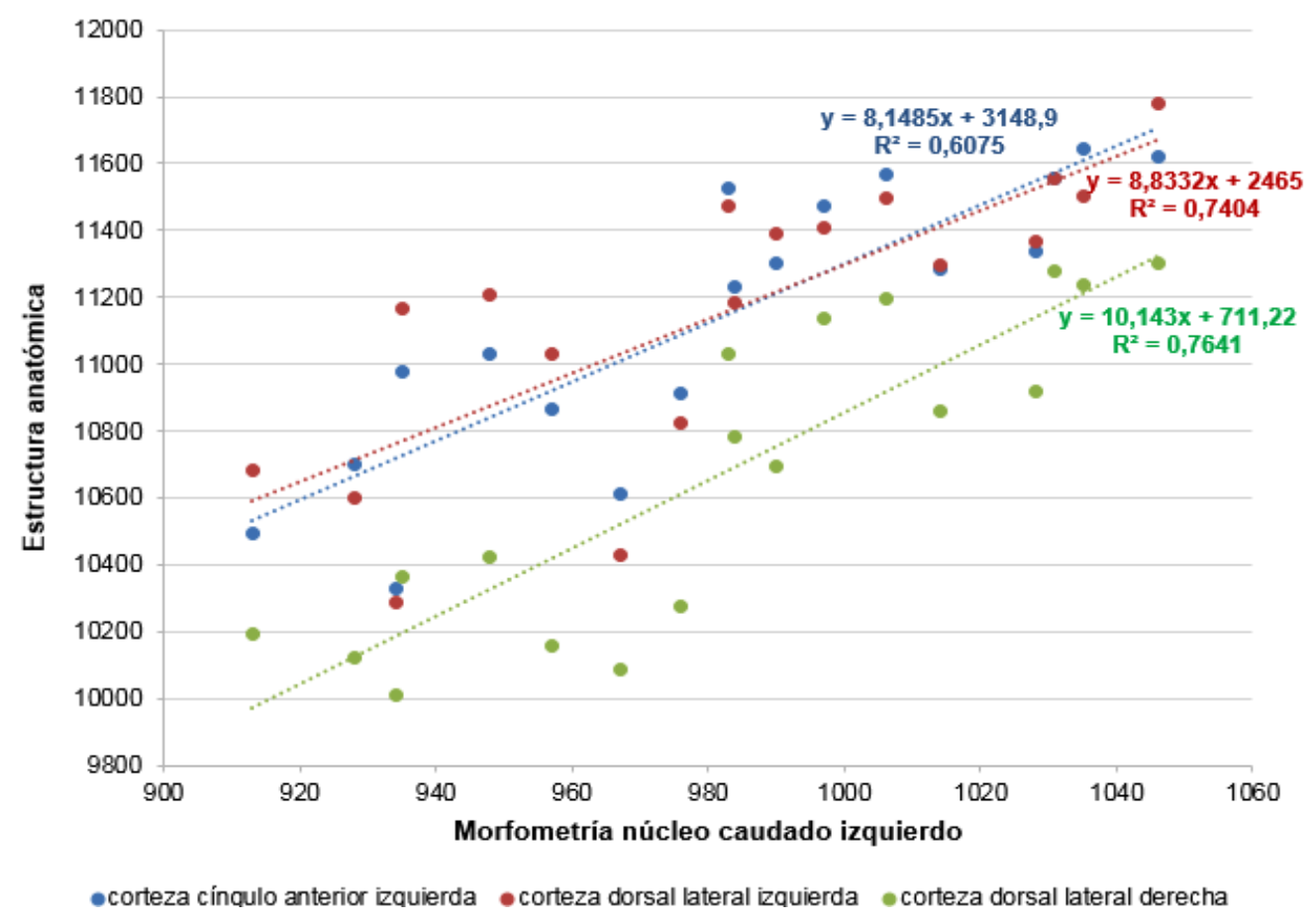

Fig. 9. Correlación entre la morfometría del núcleo caudado izquierdo y la cuantificación morfométrica de las cortezas del cínguloanterior izquierdo y dorsal lateral bilaterales en pacientes viviendo con VIH con apatía. 


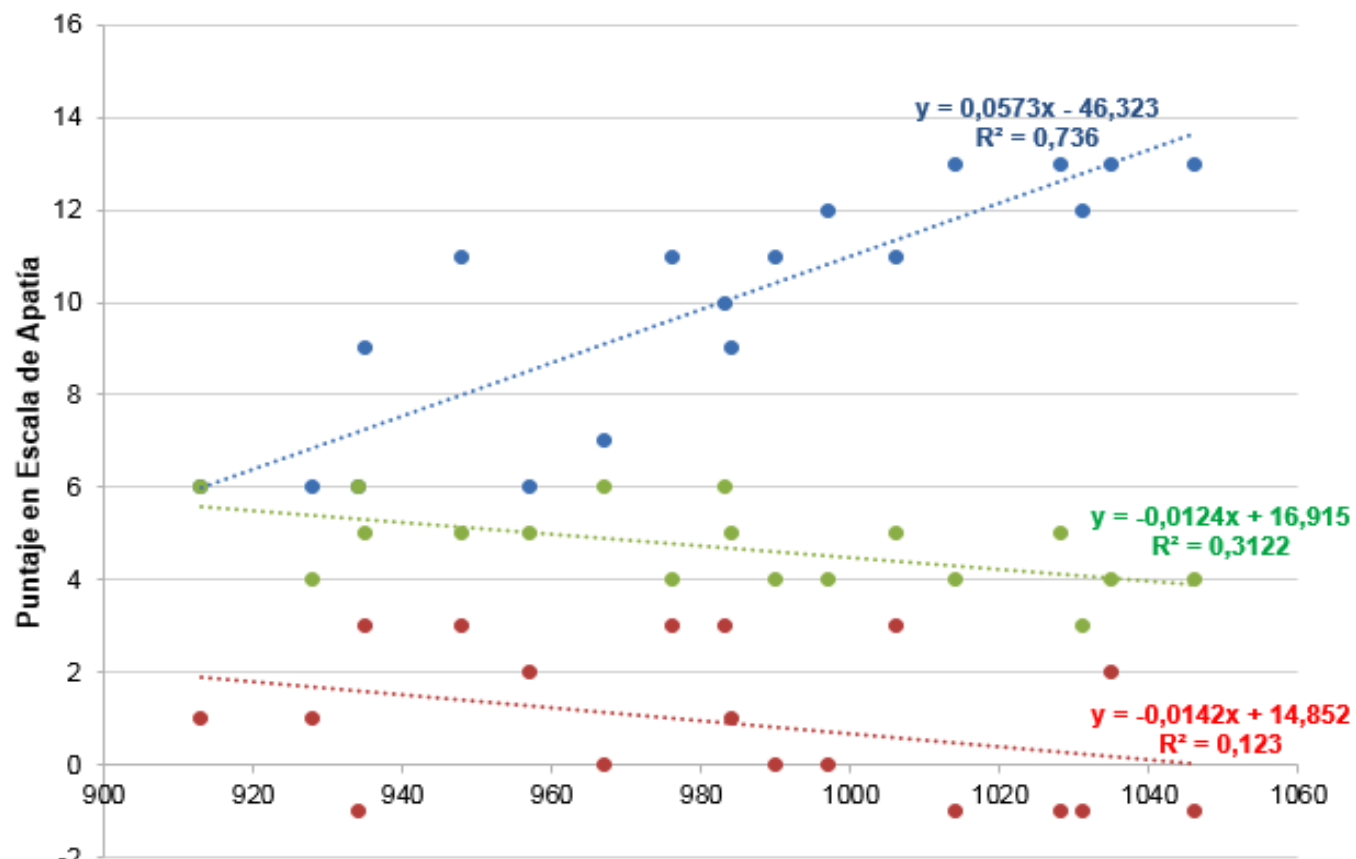

Morfometría núcleo caudado izquierdo

-AES-C subescala cognitiva $\bullet$ AES-C subescala conductual $\quad$ AES-C subescala emocional

Fig.10. Correlación entre la morfometría del núcleo caudado izquierdo y los puntajes en la Escala de Apatía en pacientes viviendo con VIH con apatía.

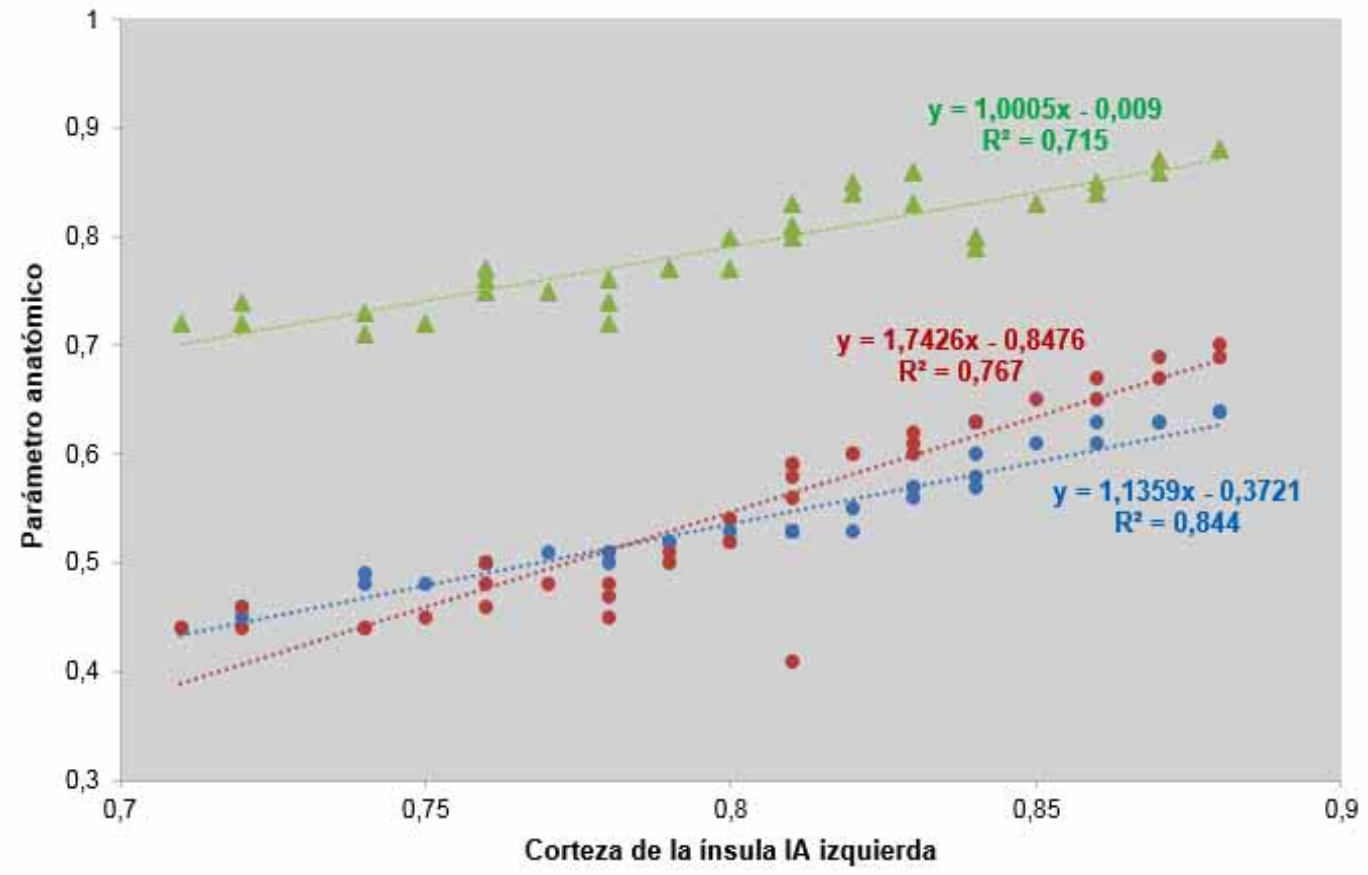

-núcleo caudado NC1 izquierdo •corteza del cíngulo anterior AC2 izquierda s corteza frontal lateral SPF1 izquierda

Fig. 11. Correlación entre la perfusión de la corteza de la ínsula IA izquierda con la perfusión del caudado NC1, cíngulo anterior AC2 y corteza frontal lateral SPF1 izquierdos en pacientes viviendo con VIH con apatía. 


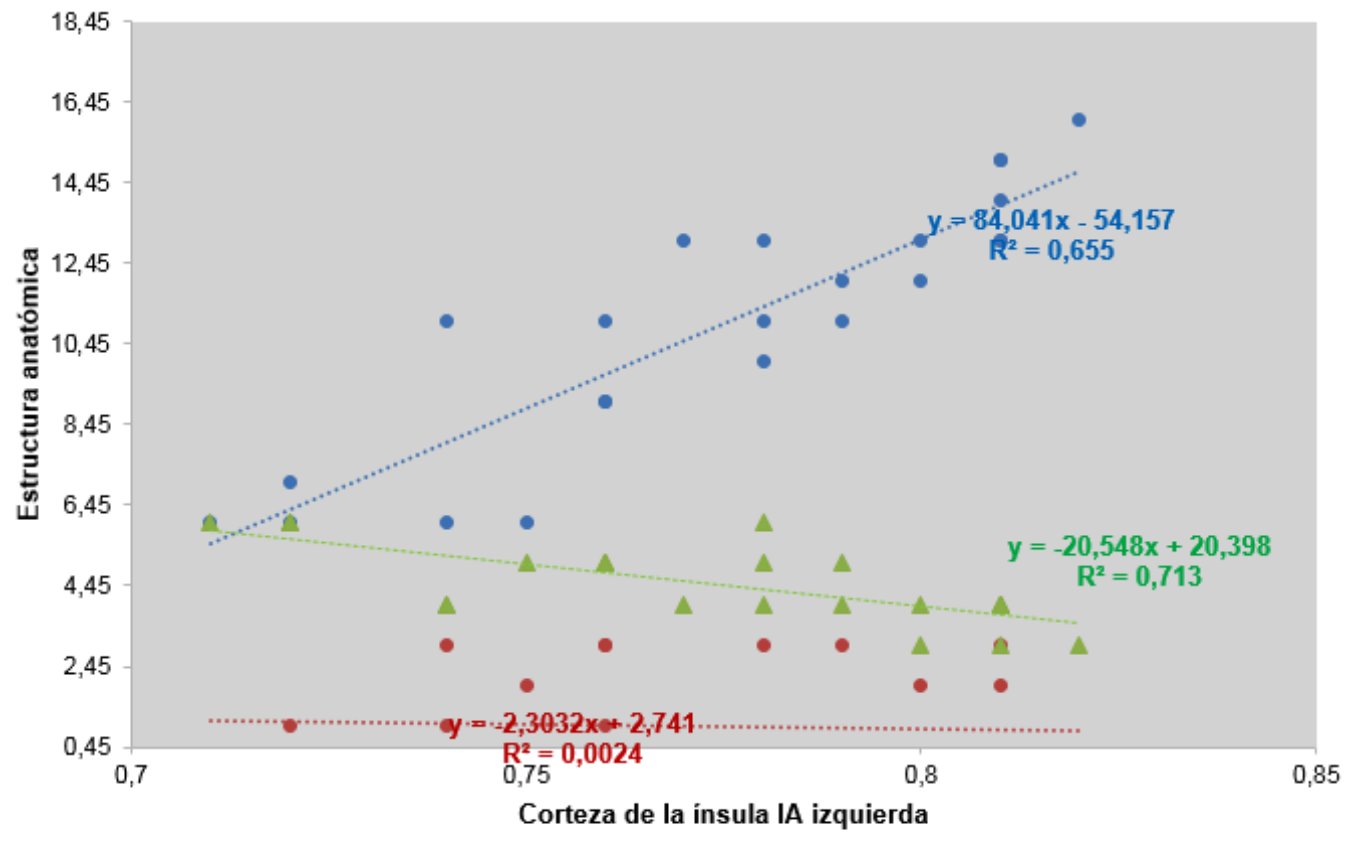

- AES-C subescala cognitiva $\quad$ AES-C subescala conductual $\quad \triangle A E S-C$ subescala emocional

Fig. 12. Correlación entre la perfusión de la corteza de la ínsula IA izquierda con el puntaje en las subescalas de la Escala de Apatía en pacientes viviendo con VIH con apatía.

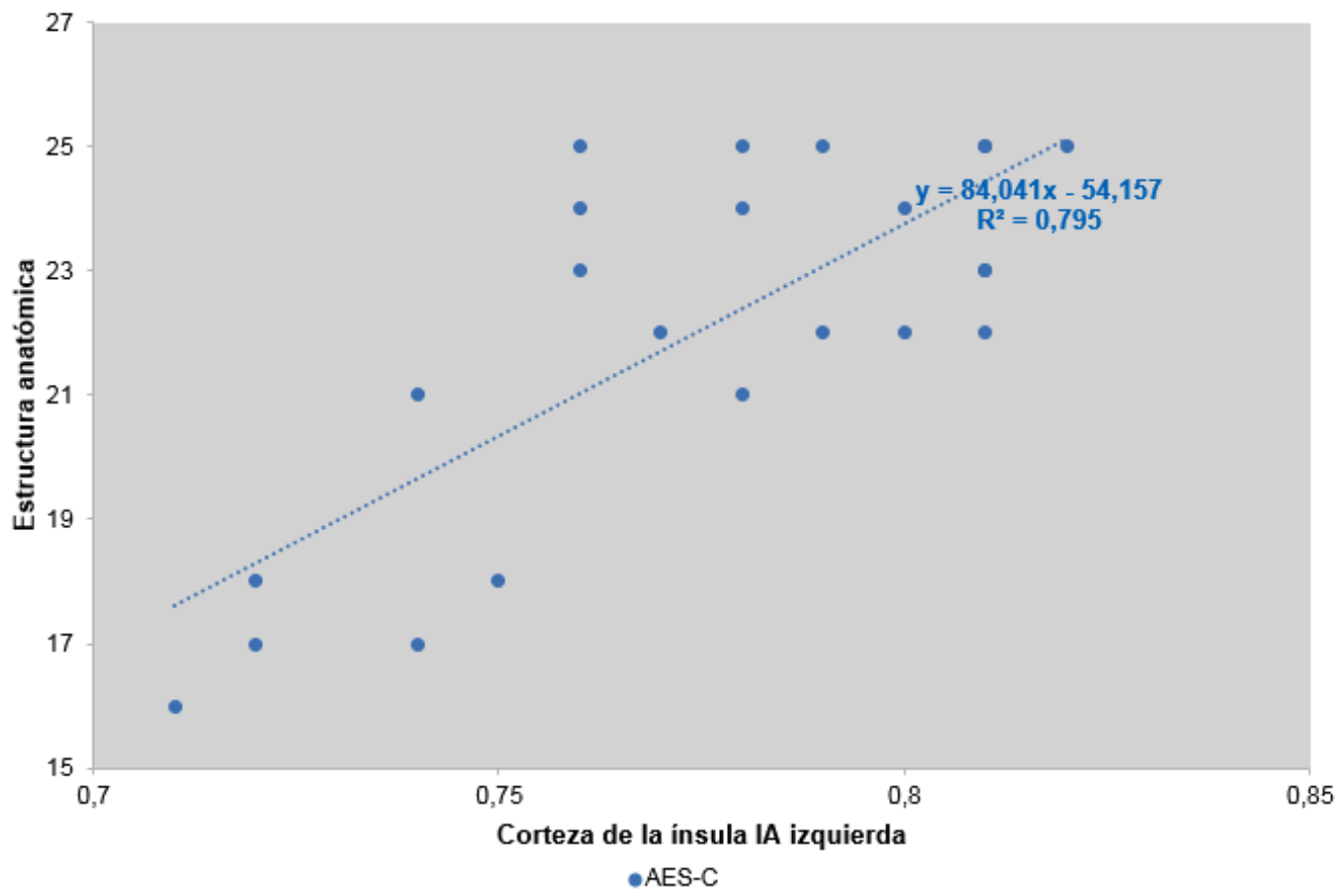

Fig. 13. Correlación entre la perfusión de la corteza de la ínsula IA izquierda con el puntaje total en la Escala de Apatía en pacientes viviendo con VIH con apatía. 


\section{DISCUSIÓN}

La apatía representa la pérdida de la motivación, con implicancia conductual, emocional y cognitiva, permitiendo objetivar la reducción de la acción hacia un objetivo. A partir de los trabajos de Robert Marin (Marin, 1996) se le dio una entidad propia e independiente de la depresión, con un complejo nuclear caracterizado por la pérdida de motivación y una fisiopatología subyacente provista por mecanismos heterogéneos (Starkstein \& Leentjens, 2008).

Stuss \& van Reekum (2000) propusieron dividir la apatía en 3 subtipos en función a la fase alterada: emocional, cognitiva y conductual; y en el 2006 Levy modifica esta división y agrega como causal a los factores externos (justificando que debido a ellos puede revertir o autoactivarse) (Levy \& Czernecki, 2006).

Las subdivisiones de la apatía difieren en el sustrato neurobiológico implicado. La apatía emocional, con incapacidad para asociar señales afectivas y emocionales con actos en curso, se relaciona con el circuito límbico córticotálamo-estriatal que incluye zonas órbito-mediales de la corteza prefrontal y la zona límbica de los núcleos basales (estriado y pálido ventrales); la apatía cognitiva, relacionada con alteración en las funciones ejecutivas, se relaciona con la zona lateral de la corteza prefrontal y porciones dorsales de los núcleos caudado y pálido; y la apatía por disfunción de la auto-activación, con dificultades en iniciar acciones o pensamientos automotivados (sólo aquellos en respuesta a estímulos externos, relacionados con las zonas cognitivas y límbicas de los núcleos basales y en menor medida con la zona dorsomedial de la corteza prefrontal) (Starkstein \& Leentjens, 2008; Levy \& Dubois, 2006; Zamboni, et al. 2008).

El presente estudio registró correlación entre la apatía, la morfometría prefrontal y el núcleo caudado. Por lo tanto, se considera que el compromiso del circuito prefrontal dorsomedial-subcortical se asocia con los trastornos de la función ejecutiva (planeamiento y organización de nuevos objetivos); así como el circuito cingular-subcortical se vincula con la motivación y su trastorno.

La motivación se definió como el impulso que conduce a una persona a elegir y realizar una acción entre las alternativas que se presentan en una determinada situación. En la motivación intrínseca se realiza una actividad por incentivos internos (el placer) y en la extrínseca el estímulo es externo. Nuestros casos evaluados no evidencian compromiso significativo del cuerpo amigdalino pero sí del núcleo caudado, no siendo relevante la conexión cingular-amigdalina.
La corteza insular anterior, que se conecta con tálamo, estriado ventral, núcleo amigdalino y corteza prefrontal, se vio involucrada en el procesamiento de la información convergente que permite producir un contexto emocionalmente relevante para la experiencia emocional. La ínsula se vio involucrada en deseos conscientes y se la ha relacionado con la integración de la información, relacionando estados corporales con procesos emocionales y cognitivos de orden superior. En nuestra investigación se registró compromiso significativo insular anterior, que correlacionó con la psicopatología de la apatía, vinculándola con la afectación de la motivación intrínseca.

Si bien se detectó una desviación morfométrica de la sustancia blanca (dorsal lateral y del cíngulo anterior), ésta fue a nivel del hemisferio derecho y no presentó correlación con la manifestación clínica de apatía de los sujetos. Esta desviación se interpreta como parámetro neuroevolutivo, indicador de progresión y severidad del compromiso de la conectividad, que implica procesamiento.

Destacamos que en nuestro estudio las neuroimágenes funcionales por SPECT y su análisis semicuantitativo de los núcleos caudados mostraron que se hallaron hipoperfundidos de forma absoluta en sus porciones ventrales, con diferenciación hemisférica. Este hallazgo es de importancia puesto que en el deterioro cognitivo asociado con el VIH el patrón imagenológico de esta estructura es asimétrico (Ances et al., 2006; Mazzoglio \& Nabar, 2014; Tornese \& Mazzoglio y Nabar, 2008, 2014; ), mientras que en los casos de pacientes con trastorno depresivo (excluyendo el melancólico) el patrón de hipoperfusión es global y simétrico a nivel cortical frontal (Schwartz et al., 1994; Tornese y Mazzoglio y Nabar, 2010, 2012). No obstante de la importancia por el patrón neuroimagenológico, en tanto predictor y correlativo con los posteriores hallazgos estructurales, la perfusión de los caudados no se relacionaría con el nivel de CD4 en los pacientes según reportes de investigadores sino con los mediadores de respuesta inmunológica (Tornese y Mazzoglio y Nabar, 2014; Mazzoglio y Nabar, 2007; Paul et al., 2005a). Y la apatía se halló asociada con la evolución del trastorno neuropsiquiátrico y su alteración morfológica cerebral (Paul et al., 2005b).

Nuestra investigación registró que la perfusión de la ínsula anterior izquierda fue correlativa y de mayor impacto con la del caudado ipsilateral $\left(\mathrm{r}^{2}=0,84\right)$ y proporcional a la severidad en el test de apatía $\left(r^{2}=0,83\right)$. Entonces, tanto el comportamiento neurofuncional de los núcleos caudados como la hipoperfusión de la corteza de la ínsula anterior a predominio izquierdo y la normalidad en los rangos de perfusión amigdalina, son nuestros hallazgos de importancia y significación en el cuadro de apatía en pacientes VIH+. 


\section{CONCLUSIONES}

En la cohorte evaluada de sujetos con VIH y apatía hallamos un significativo compromiso funcional de la corteza insular anterior, correlativo con la afectación funcional y morfométrica de los núcleos caudados. Este compromiso en las neuroimágenes funcionales se asoció y correlacionó con las manifestaciones clínicas de la apatía, determinado por los test implementados.

La implicancia de la corteza insular sugiere su participación en la psicopatología de la apatía, parámetro vinculado con el déficit de interés por las actividades e iniciativas.

TORNESE, E. B. \& MAZZOGLIO Y NABAR, M. J. Morphometric and functional findings about the ínsula in HIV+ population with apathy. Int. J. Morphol., 35(1):273-286, 2017.

SUMMARY: The insular cortex is one of the components of the paralimbic zone that has connections with cortical and subcortical areas. The study in people living with HIV (PLHIV), in which apathy is frequent, implicated the structure as a modulator of emotional and executive responses. The objective is to make a description based on morphometry and functionality of the insula in relation to cortical and subcortical structures in PLHIV with apathy compared to controls and compared to PLHIV without apathy, in order to determine its implication. We studied 23 brains of male PLHIV with apathy according to neuropsychiatric evaluations. Magnetic resonance imaging (MRI) with cognitive quantification protocol and Single photon emission tomography (SPECT) to evaluate cortical perfusion were used applied to: frontal cortices, insular cortex, caudate nuclei and amygdaloid bodies. We recorded a significant morphometric reduction of the left anterior cingulate cortex, left caudate nucleus and dorso-lateral cortex in PLHIV with apathy; anterior insula cortex recorded a non-significant reduction $(\mathrm{p}=0.4)$. Functional analysis showed hypoperfusion in the left anterior cingulum cortex, left anterior insular region and caudate nucleus's perfusion were assymetrically; relative hypoperfusion were found in right hemisphere regions. The perfusion of the left anterior insula was correlated with ipsilateral caudate and proportional to the severity in the apathy test. We concluded in the cohort evaluated patients living with HIV and apathy found a significant functional compromise of the anterior insular cortex, correlated with morphometric and functional impairment of the caudate nuclei. The implication of the insular cortex suggests their participation in the psychopathology of apathy, parameter linked with the deficit of interest in the activities and initiatives.

KEY WORDS: Insula; Apathy; HIV; MR; SPECT.

\section{REFERENCIAS BIBLIOGRÁFICAS}

Ances, B. M.; Roc, A. C.; Wang, J.; Korczykowski, M., Okawa, J.; Stern, J.; Kim, J.; Wolf, R.; Lawler, K.; Kolson, D. L. \& Detre, J. A. Caudate blood flow and volume are reduced in HIV+ neurocognitively impaired patients. Neurology, 66(6):862-6, 2006.

Augustine, J. R. Circuitry and functional aspects of the insular lobe in primates including humans. Brain Res. Brain Res. Rev., 22(3):229-44, 1996.

Chang, L. T. Attenuation correction and incomplete projection in Single Photon Emission Computed Tomography. I. E. E. E. Trans. Nucl. Sci., 26(2):2780-9, 1979.

Crespo-Facorro, B.; Kim, J.; Andreasen, N. C.; O'Leary, D. S.; Bockholt, H. J. \& Magnotta, V. Insular cortex abnormalities in schizophrenia: a structural magnetic resonance imaging study of first-episode patients. Schizophr. Res., 46(1):35-43, 2000.

Critchley, H. D.; Wiens, S.; Rotshtein, P.; Ohman, A. \& Dolan, R. J. Neural systems supporting interoceptive awareness. Nat. Neurosci., 7(2):18995, 2004.

Etkin, A. \& Wager, T. D. Functional Neuroimaging of Anxiety: A Functional neuroimaging of anxiety: a meta-analysis of emotional processing in PTSD, social anxiety disorder, and specific phobia. Am. J. Psychiatry, 164(10):1476-88, 2007.

Folstein, M. F.; Folstein, S. E. \& McHugh, P. R. "Mini-mental state". A practical method for grading the cognitive state of patients for the clinician. J. Psychiatr. Res., 12(3):189-98, 1975.

Guy, W. ECDEU Assessment Manual for Psychopharmacology. Rockville, U.S. Dept. of Health, Education, and Welfare, Public Health Service, Alcohol, Drug Abuse, and Mental Health Administration, National
Institute of Mental Health, Psychopharmacology Research Branch, Division of Extramural Research Programs, 1976.

Kroenke, K. \& Spitzer, R. L. The PHQ-9: A new depression diagnostic and severity measure. Psychiatr. Ann., 32(9):509-15, 2002.

Levy, R. \& Czernecki, V. Apathy and the basal ganglia. J. Neurol., 253 Suppl. 7:VII54-61, 2006.

Levy, R. \& Dubois, B. Apathy and the functional anatomy of the prefrontal cortex-basal ganglia circuits. Cereb. Cortex, 16(7):916-28, 2006.

Lindauer, R. J.; Booij, J.; Habraken, J. B.; van Meijel, E. P.; Uylings, H. B.; Olff, M.; Carlier, I. V.; den Heeten, G. J.; van Eck-Smit, B. L. \& Gersons, B. P. Effects of psychotherapy on regional cerebral blood flow during trauma imagery in patients with post-traumatic stress disorder: a randomized clinical trial. Psychol. Med., 38(4):543-54, 2008.

Lorberbaum, J. P.; Kose, S.; Johnson, M. R.; Arana, G. W.; Sullivan, L. K.; Hamner, M. B.; Ballenger, J. C.; Lydiard, R. B.; Brodrick, P. S.; Bohning, D. E. \& George, M. S. Neural correlates of speech anticipatory anxiety in generalized social phobia. Neuroreport, 15(18):2701-5, 2004.

Marin, R. S. Apathy: Concept, Syndrome, Neural Mechanisms, and Treatment. Semin. Clin. Neuropsychiatry, 1(4):304-14, 1996.

Mazzoglio y Nabar, M. J. \& Tornese, E. B. Anticuerpos Anticardiolipinas, Deterioro Cognitivo y Flujo Sanguíneo Cerebral en Pacientes Masculinos VIH Positivos. Buenos Aires, Secretaria de Ciencia y Técnica, Facultad de Medicina, Universidad de Buenos Aires, 2007.

Paul, R.; Flanigan, T. P.; Tashima, K.; Cohen, R.; Lawrence, J.; Alt, E.; Tate, D.; Ritchie, C. \& Hinkin, C. Apathy correlates with cognitive function but not CD4 status in patients with human immunodeficiency virus. J. Neuropsychiatry Clin. Neurosci., 17(1):114-8, 2005 a. 
Paul, R. H.; Brickman, A. M.; Navia, B.; Hinkin, C.; Malloy, P. F.; Jefferson, A. L.; Cohen, R. A.; Tate, D. F. \& Flanigan, T. P. Apathy is associated with volume of the nucleus accumbens in patients infected with HIV. $J$. Neuropsychiatry Clin. Neurosci., 17(2):167-71, 2005b.

Pruessner, J. C.; Li, L. M.; Serles, W.; Pruessner, M.; Collins, D. L.; Kabani, N.; Lupien, S. \& Evans, A. C. Volumetry of hippocampus and amygdala with high-resolution MRI and three-dimensional analysis software: minimizing the discrepancies between laboratories. Cereb. Cortex, 10(4):433-42, 2000.

Reisberg, B.; Ferris, S. H.; de Leon, M. J. \& Crook, T. The Global Deterioration Scale for assessment of primary degenerative dementia. Am. J. Psychiatry, 139(9):1136-9, 1982.

Schmidt-Wilcke, T.; Luerding, R.; Weigand, T.; Jürgens, T.; Schuierer, G.; Leinisch, E. \& Bogdahn, U. Striatal grey matter increase in patients suffering from fibromyalgia--a voxel-based morphometry study. Pain, 132 Suppl. 1:S109-16, 2007.

Schunck, T.; Erb, G.; Mathis, A.; Jacob, N.; Gilles, C.; Namer, I. J.; Meier, D. \& Luthringer, R. Test-retest reliability of a functional MRI anticipatory anxiety paradigm in healthy volunteers. J. Magn. Reson. Imaging, 27(3):459-68, 2008.

Schwartz, R. B.; Komaroff, A. L.; Garada, B. M.; Gleit, M.; Doolittle, T. H.; Bates, D. W.; Vasile, R. G. \& Holman, B. L. SPECT imaging of the brain: comparison of findings in patients with chronic fatigue syndrome, AIDS dementia complex, and major unipolar depression. A. J. R. Am. J. Roentgenol., 162(4):943-51, 1994.

Sheehan, D. V.; Lecrubier, Y.; Sheehan, K. H.; Amorim, P.; Janavs, J.; Weiller, E.; Hergueta, T.; Baker, R. \& Dunbar, G. C. The MiniInternational Neuropsychiatric Interview (M.I.N.I.): the development and validation of a structured diagnostic psychiatric interview for DSMIV and ICD-10. J. Clin. Psychiatry, 59 Suppl. 20:22-33, 1998.

Simmons, A.; Strigo, I.; Matthews, S. C.; Paulus, M. P. \& Stein, M. B. Anticipation of aversive visual stimuli is associated with increased insula activation in anxiety-prone subjects. Biol. Psychiatry, 60(4):402-9, 2006.

Starkstein, S. E. \& Leentjens, A. F. The nosological position of apathy in clinical practice. J. Neurol. Neurosurg. Psychiatry, 79(10):1088-92, 2008.

Stoléru, S.; Grégoire, M. C.; Gérard, D.; Decety, J.; Lafarge, E.; Cinotti, L.; Lavenne, F.; Le Bars, D.; Vernet-Maury, E.; Rada, H.; Collet, C.; Mazoyer, B.; Forest, M. G.; Magnin, F.; Spira, A. \& Comar, D. Neuroanatomical correlates of visually evoked sexual arousal in human males. Arch. Sex. Behav., 28(1):1-21, 1999.

Stuss, D. \& Van Reekum, R. Differentiation of States and Causes of Apathy. The Neuropsychology of Emotion. Oxford, Oxford University Press, 2000

Tanaka, F.; Vines, D.; Tsuchida, T.; Freedman, M. \& Ichise, M. Normal patterns on $99 \mathrm{mTc}-\mathrm{ECD}$ brain SPECT scans in adults. J. Nucl. Med., 41(9): 1456-64, 2000.

Tornese, E. B. \& Mazzoglio y Nabar, M. J. Depresión en Masculinos con Demencia debida a VIH. Mendoza, VII Congreso Mundial de Estados Depresivos-VII World Congress on Depressive Disorders, 2010.

Tornese, E. B. \& Mazzoglio y Nabar, M. J. Neuroanatomía por SPECT en Varones VIH+. Ciudad Autónoma de Buenos Aires, $11^{\circ}$ Congreso Argentino de Neurociencia, 2008.

Tornese, E. B. \& Mascitti, T. Parámetros del Test Barcelona Predictivos de Esquizofrenia. Ciudad Autónoma de Buenos Aires, I Congreso Nacional de Neuropsicología, 1994.

Tornese, E. B. \& Mazzoglio y Nabar, M. J. Cognición Social, Anatomía Clínica e Inmunología en VIH Positivos. Ciudad Autónoma de Buenos Aires, XXVII Congreso de la Asociación Psiquiátrica de América Latina (APAL), 2012.

Tornese, E. B. \& Mazzoglio y Nabar, M. J. Inmunología Aplicada a los Trastornos Cognitivos de Masculinos VIH+. Salta, II Congreso Nacional de SIDA, 2009.

Tornese, E. B. \& Mazzoglio y Nabar, M. J. Morfología de la Corteza Insular en Pacientes con Demencia tipo Alzheimer de Ambos Sexos. Ciudad Autónoma de Buenos Aires, $14^{\circ}$ Congreso Argentino de
Neurociencia y Salud Mental, 2012

Tornese, E. B. \& Mazzoglio y Nabar, M. J. Perfil Biopsicosocial en Infectados Masculinos por VIH. Mar del Plata, XXVII Congreso Argentino de Psiquiatría, 2012.

Tornese, E. B. \& Mazzoglio y Nabar, M. J. Predictores Fronto-Estriados en la Demencia debida a Enfermedad por VIH en Masculinos. San Juan, III Congreso Nacional de SIDA, SAISIDA, 2011.

Wible, C. G.; Shenton, M. E.; Hokama, H.; Kikinis, R.; Jolesz, F. A.; Metcalf, D. \& McCarley, R. W. Prefrontal cortex and schizophrenia. A quantitative magnetic resonance imaging study. Arch. Gen. Psychiatry, 52(4):279-88, 1995.

Zamboni, G.; Huey, E. D.; Krueger, F.; Nichelli, P. F. \& Grafman, J. Apathy and disinhibition in frontotemporal dementia: Insights into their neural correlates. Neurology, 71(10):736-42, 2008.

Dirección para Correspondencia:

Martín Javier Mazzoglio y Nabar

Laboratorio de Neuroanatomía aplicada a la Neurociencia

$3^{\circ}$ Cátedra de Anatomía

Facultad de Medicina

Universidad Nacional de Buenos Aires

Paraguay, 2055, 4o piso, Sector Uriburu

CP 1121

Buenos Aires

ARGENTINA

Email: mazzoglioynabar@hotmail.com

Recibido : 26-12-2016

Aceptado: $30-12-2016$ 